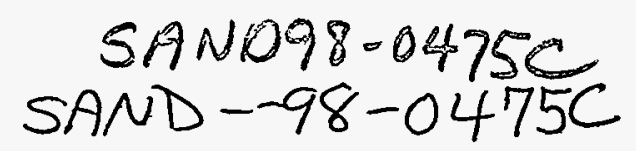

\title{
HIGH GAIN GaAs SWITCH LONGEVITY
} PHOTOCONDUCTIVE SEMICONDUCTOR SWITCHES: RECIVED

\author{
G. M. Loubriel, F. J. Zutavern, A. Mar, A. G. Baca, \\ H. P. Hjalmarson, M. W. O'Malley, G. J. Denison, and W. D. Helgeson \\ High Power Electromagnetics Department, MS 1153 \\ Sandia National Laboratories \\ Albuquerque, NM 87185-1153 \\ Tel. (505) 845-7096 \\ D. J. Brown \\ Ktech Corporation \\ Albuquerque, NM 87110

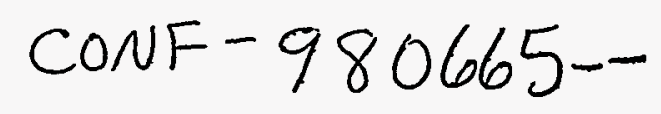 \\ R. L. Thornton and R. M. Donaldson \\ Xerox Palo Alto Research Center \\ Palo Alto, CA 94304
}

JUL 071998

\begin{abstract}
Optically activated, high gain GaAs switches are being tested for many different pulsed power applications that require long lifetime (longevity). The switches have $p$ and $n$ contact metallization (with intentional or unintentional dopants) configured in such a way as to produce $p-i-n$ or $n-$ $i-n$ switches. The longevity of the switches is determined by circuit parameters and by the ability of the contacts to resist erosion. This paper will describe how the switches performed in test-beds designed to measure switch longevity. The best longevity was achieved with switches made with diffused contacts, achieving over 50 million pulses at $10 \mathrm{~A}$ and over 2 million pulses at $80 \mathrm{~A}$.
\end{abstract}

\section{Introduction on High Gain GaAs Switches}

High gain photoconductive semiconductor switches (PCSS) offer switching improvements in voltage, current, rise time, jitter, optical activation, size, and cost over other switching options. These switches have been investigated for use in many high voltage applications such as: ground penetrating radar $^{1}$ (GPR) and high power microwave generation, switches for firing sets for weapons, ${ }^{2}$ drivers for laser diode arrays to allow detection of objects through fog and smoke, ${ }^{3}$ pulsers for Q-switching lasers, ${ }^{2}$ and high voltage accelerators ${ }^{4}$. They all require long switch lifetime and low jitter. For example: Q-switch drivers $\left(>10^{7}\right.$ pulses are required with sub-ns jitter), GPR $\left(>10^{7}\right.$ pulses, $200 \mathrm{ps}$ ), and drivers for laser diode arrays $\left(-10^{7}\right.$ pulses, $\left.200 \mathrm{ps}\right)$.

The GaAs switches used in this experiment are lateral switches (Figure 1) made from undoped GaAs of high resistivity $>10^{7} \Omega-\mathrm{cm}$ and metallic lands that connect the switch to an energy source and a load. The metallic contacts provide either $p$ or $n$ doped regions. The simplest $n$ and $p$ contacts are made from $\mathrm{Ni}-\mathrm{Ge}-\mathrm{Au}-\mathrm{Ni}-\mathrm{Au}$ and $\mathrm{Au}-\mathrm{Be}$ metallization, respectively. The insulating region separating the two contacts (the gap, in analogy to spark gaps) has a length that varies from $0.2 \mathrm{~mm}$ to $3.4 \mathrm{~cm}$ depending on switched voltage. Because of high electric fields the switches are immersed in a dielectric liquid.

There are three aspects of high gain PCSS that we will briefly discuss here. First, high gain is achieved by creation of electron hole pairs by impact ionization or avalanche carrier generation. Because many carriers are produced per absorbed photon, switches operating in this mode require extremely low energy optical pulses for triggering. We have triggered $100 \mathrm{kV}$ gallium arsenide (GaAs) PCSS, with as little as $90 \mathrm{~nJ}$. Another aspect of high gain is a voltage drop during conduction. Once triggering is initiated, the switch continues to generate carriers until the field across the switch drops to $4-6 \mathrm{kV} / \mathrm{cm}$ (depending upon the type of GaAs). We originally called this switching mode "lock-on" to describe this effect. In series with a current limiting resistor, the switch will conduct whatever current is necessary to maintain a constant "lock-on" voltage/field. A final feature of high gain PCSS is that the current forms in filaments which are easily observed with a near infra-red sensitive camera. These filaments are the reason why longevity is difficult to achieve. Table 1 shows the best results we have obtained with the high gain GaAs switches. To understand and develop high gain PCSS many experiments have been performed. ${ }^{5}$

* This work was supported by the United States Department of Energy under contract DE-AC04-94AL85000. Sandia is a multiprogram laboratory operated by Sandia Corporation, a Lockheed Martin Company, for the United States Department of Energy.

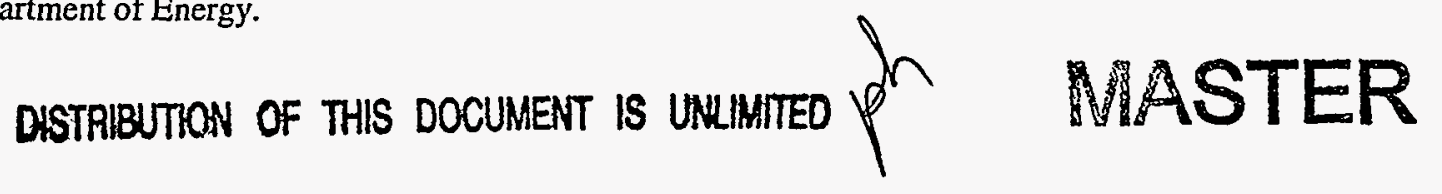




\section{DISCLAIMER}

This report was prepared as an account of work sponsored by an agency of the United States Government. Neither the United States Government nor any agency thereof, nor any of their employees, makes any warranty, express or implied, or assumes any legal liability or responsibility for the accuracy, completeness, or usefulness of any information, apparatus, product, or process disclosed, or represents that its use would not infringe privately owned rights. Reference herein to any specific commercial product, process, or service by trade name, trademark, manufacturer, or otherwise does not necessarily constitute or imply its endorsement, recommendation, or favoring by the United States Government or any agency thereof. The views and opinions of authors expressed herein do not necessarily state or reflect those of the United States Government or any agency thereof. 


\section{DISCLAIMER}

Portions of this document may be illegible electronic image products. Images are produced from the best available original document. 


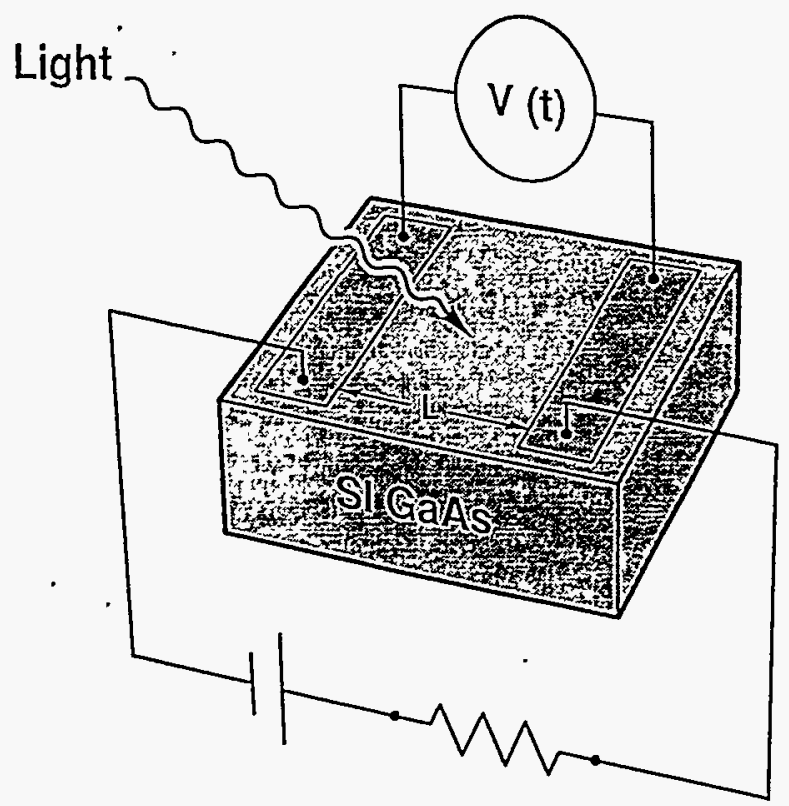

Figure 1. Schematic of the lateral semi-insulating (SI) GaAs switches used in this study. In this circuit the switch is being used to discharge a capacitor into a resistive load.

Table 1. Results of tests with high gain GaAs switches. The second column is the best results obtained in various, independent tests. The third column shows the results from one system.

\begin{tabular}{|l|c|c|}
\hline $\begin{array}{c}\text { Table I } \\
\text { Parameter }\end{array}$ & $\begin{array}{c}\text { Best cases: not } \\
\text { simultaneous }\end{array}$ & $\begin{array}{c}\text { Simultaneous } \\
\text { Results }\end{array}$ \\
\hline Switch Voltage (kV) & 220 & 100 \\
\hline Switch Current (kA) & 8 & 1.26 \\
\hline Peak Power (MW) & 650 & 48 \\
\hline Rise time (ps) & 430 & 430 \\
\hline R-M-S jitter (ps) & 50 & 150 \\
\hline Trigger Energy (nJ) & 2 & 180 \\
\hline Repetition Rate (Hz) & 1,000 & 1,000 \\
\hline Elect. Field (kV/cm) & 100 & 67 \\
\hline $\begin{array}{l}\text { Device Lifetime } \\
\text { \# pulses) }\end{array}$ & $\begin{array}{c}50,000,000 \\
\text { (at 2.2 kV, 13 A) }\end{array}$ & $\begin{array}{c}50,000 \\
\text { (at 77 kV) }\end{array}$ \\
\hline
\end{tabular}

\section{Switch Longevity}

We have performed extensive switch longevity tests using a fixed circuit. ${ }^{6}$ The circuit has a pulsed power source that charges a $50 \Omega$ coaxial cable to a few $\mathrm{kV}$ (up to $20 \mathrm{kV}$ ) in about $1 \mu \mathrm{s}$ and the total pulse width is about $2 \mu \mathrm{s}$. A diode stack is placed between the power source and the coaxial cable such that, under certain conditions, the switch only discharges the energy in the coaxial line. The duration of the current pulse is adjustable from $1 \mathrm{~ns}$ to $30 \mathrm{~ns}$. For this study the current pulse duration was set at 3.5 ns. To trigger the switches we use laser diode arrays with a pulse duration of about $20 \mathrm{~ns}$ and a total energy of about $1 \mu \mathrm{J}$. The light energy was

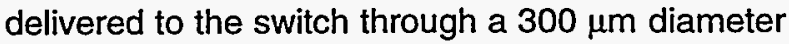
optical fiber.

One can increase the longevity of a switch by using multiple fibers to share the current amongst various filaments or by moving the fibers during the test to avoid a damaged area and continue switching. Our methodology in this paper is to report on improvements in switch longevity with one (or two) fixed optical fiber(s) to obtain a longevity for a fixed current per filament. For systems that may require more current multiple filaments may be triggered with multiple fibers.

Types of damage: The longevity tests have determined that, in most cases, the damage to the $p$ contact is larger than that of the $n$ contact. There are three types of damage to the switches: damage of the semiconductor to metal interface which initially appears as a trench, metal erosion, and damage in the GaAs away from the contacts (in the gap between the contacts). The trench damage precedes all other damage and is visible with a scanning electron microscope (SEM) after a few hundred pulses. Figures 2 and 3 show metal contact erosion and trench damage after 25,000 pulses and 100,000 pulses. Metal contact erosion is an important damage mechanism since it is the main cause of degradation of switching conditions and, ultimately, causes the switch to stop functioning. Gap damage is rare and, if it occurs, is normally after considerable contact erosion.

Diffuse triggering: In all the tests that we have described, the switch was triggered with a single laser diode array via an optical fiber whose output was aimed at the center of the switch. A typical filament that results from such a trigger light distribution is diffuse in the center of the switch. By moving the fiber to illuminate near one contact, we found out that the damage to the contact was reduced by making the current filaments diffuse near the contacts. This results in over 10,000,000 pulses with no damage. Since continued testing at $100 \mathrm{~Hz}$ is too time consuming, we are continuing tests at either higher currents with diffuse filaments or with focused filaments at these lower currents. 


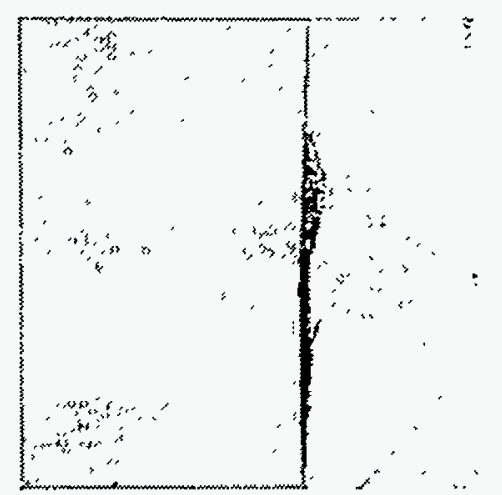

Figure 2. Photograph of damage to a standard $p$ $i-n$ switch after 25,000 pulses. The field of view is $0.7 \mathrm{~mm}$ wide by $1.2 \mathrm{~mm}$ high. The switch has a gap of $1.0 \mathrm{~mm}$ (in the horizontal direction) and was tested at 12 to $14 \mathrm{~A}(2.2 \mathrm{kV})$. The damage is on the $p$ side (shown) and is mostly contact damage.

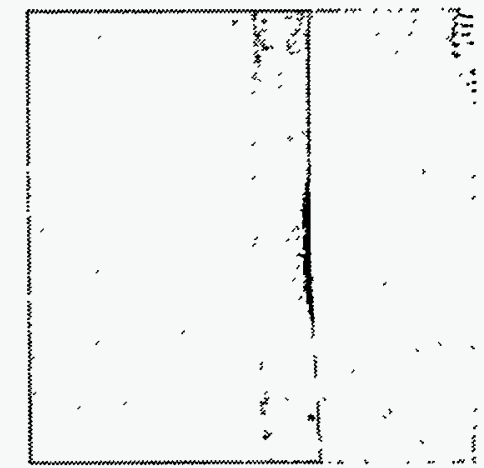

Figure 3. Photograph of damage to an ion implanted switch after 100,000 pulses. The field of view is $0.7 \mathrm{~mm}$ wide by $1.2 \mathrm{~mm}$ high. The switch has a gap of $1.0 \mathrm{~mm}$ (in the horizontal direction) and was tested at 12 to $14 \mathrm{~A}(2.2 \mathrm{kV})$. The ion implanted region is the shaded area that starts $100 \mu \mathrm{m}$ to the left of the p contact and extends under the whole area of the contact. The damage here is mostly trench damage.

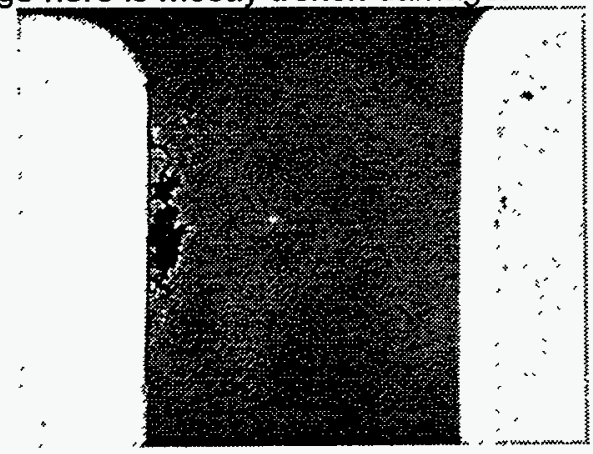

Figure 4. Photograph showing the damage to a 1 $\mathrm{mm}$ gap diffused switch after 50 million pulses. The non- diffused $n$ contact (left) is the most damaged. The $p$ contact and the diffused region show no damage. For scale, the diffused region extends 100 microns into the gap.
Ion implantation: Another way to reduce the carrier density in a filament as it crosses the semiconductor to metal interface is to dope by ion implantation in the semiconductor directly underneath the contact and in a small area that extends into the gap (by $100 \mu \mathrm{m}$ in our case). This doped area is visible in figure 3. We used $\mathrm{Be}$ ions $\left(\mathrm{Be}^{+}\right.$and $\mathrm{Be}^{++}$as the dopants. $\mathrm{Be}^{+}$was accelerated at about $300 \mathrm{kV}$ resulting in a peak activated dopant concentration (of about $10^{19}$ carriers/ cc, in our case) at $0.8 \mu \mathrm{m}$ depth. The dopant concentration is smaller at all other depths. $\mathrm{Be}^{++}$penetrates twice as deep as $\mathrm{Be}^{+}$but is not as heavily doped. As shown in figure 3 ion implantation results in a factor of about 8 reduction in damage and can shift the damage from the metal to the semiconductor. The ion implantation reduces current pinching at the semiconductor to metal interface and hence it reduces carrier density in the vertical (perpendicular to the surface) direction. Our IR sensitive photographs of the filaments show that, in some cases, very little lateral spreading is observed.

Diffusion: There are three disadvantages of ion implantation: bombardment damage to the crystal lattice, a relatively shallow implanted layer (when compared to the filament diameter), and the maximum implant density is not at the surface. These disadvantages motivate the pursuit of other new switch contact structures to improve device longevity. One approach we are pursuing is deep diffusion. In this case, the acceptor species (Zinc) is deposited over the areas where the $p$ contacts are to be made, and exposed to elevated temperature. The zinc diffuses into the GaAs up to a depth of over $2 \mu \mathrm{m}$ with peak dopant density at the surface of the material (gradually decreasing with depth). This thick dopant region beneath the $p$ contacts allows the current to spread, and will aid in the formation of low resistance metal contacts. Compared to implantation, this method offers the advantages of deeper penetration of the acceptor atoms, higher doping densities $\left(>10^{19} / \mathrm{cm} 3\right)$, and minimal disruption of the crystal lattice in the doped areas.

- The switches with diffused $p$ contacts were tested at $2.1 \mathrm{kV}$ resulting in a current pulse of $13 \mathrm{~A}$ and $3 \mathrm{~ns}$. The switch was forward biased and the trigger conditions were such that the filament was not diffuse at either contact. The switch survived $>50$ million pulses. Figure 4 shows the switch damage. At higher currents and voltages, switch damage occurs in fewer pulses. The switch shown has a $1 \mathrm{~mm}$ gap (distance between the 
metal contacts). We also tested the diffused switches at higher voltages and currents using a switch with a $2.5 \mathrm{~mm}$ gap. At $9 \mathrm{kV},(80 \mathrm{~A}, 3 \mathrm{~ns})$ we obtained 2 million pulses even though two fibers were used to illuminate the $n$ contact to reduce the damage there by creating diffuse filaments. Figures 5 and 6 show the switch. Note that, again, there is no damage to the $p$ contact. The only configuration that shows damage to the diffused $p$ contact is with reverse biased switching at $5 \mathrm{kV}$ (30 A, $3 \mathrm{~ns})$. We stopped the test after only 10,000 pulses. Figure 7 shows the damage.

\section{Conclusion}

We have improved the longevity of high gain GaAs PCSS from about 25,000 pulses to 50,000,000 pulses by using diffused $p$ contacts. The longevity-limiting damage is not in the diffused $p$ contact but is in the standard Ni-Au-Ni-Ge-Au n contact metallization. Thus, we are now testing switches with diffused $p$ and $n$ contacts.

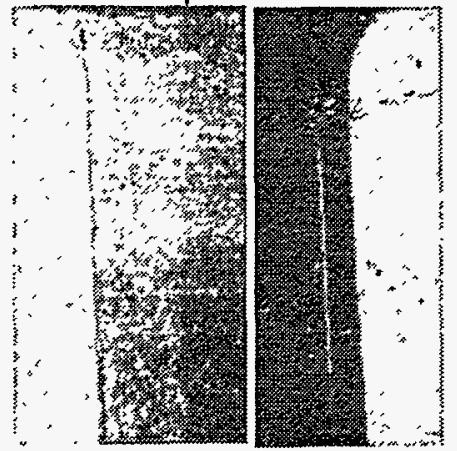

Figure 5. Photograph showing damage to the contacts of a $2.5 \mathrm{~mm}$ gap diffused switch tested at $80 \mathrm{~A}$, forward bias. The $\mathrm{n}$ contact (left) is damaged. The $p$ contact and the diffused region show no damage. For scale, the diffused region extends 100 microns into the gap.

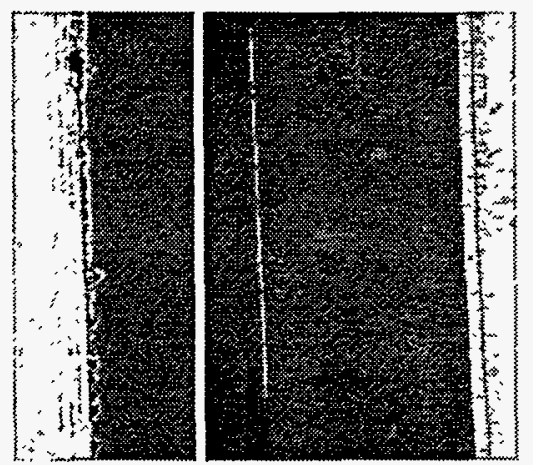

Figure 6. Damage to the contacts of a $2.5 \mathrm{~mm}$ gap diffused switch tested at $80 \mathrm{~A}$, forward bias under high magnification. The diffused region is highlighted in the right panel. Note the damage to the non- diffused $\mathbf{n}$ contact (left).

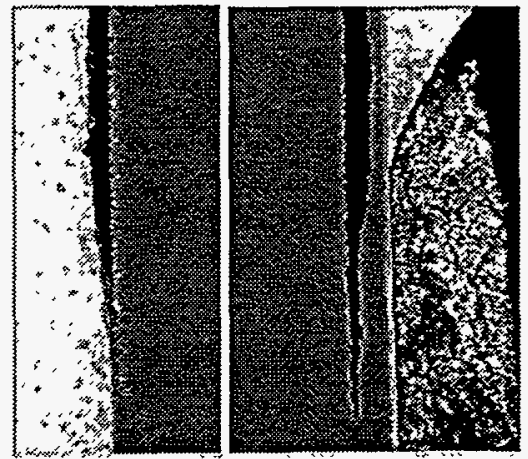

Figure 7. Damage to a $2.5 \mathrm{~mm}$ gap, reverse biased, diffused switch at $30 \mathrm{~A}$. The $n$ (left) and $p$ (right) contacts are both damaged.

\section{References}

1 G. M. Loubriel et al, "High Gain GaAs Switches for Ground Penetrating Radar", Proc. 22nd Power Modulator Symposium (IEEE, NY, 1996), Boca Raton, FL, June 24-27, 1996, pp. 165-168.

2 G. M. Loubriel et al, "Photoconductive Semiconductor Switches for Firing Sets and Electro-Optic Modulators," Proceedings of 10th IEEE Pulsed Power Conference, Albuquerque, NM, July 10-13, 1995, pp. 354- 359.

3 Fred J Zutavern et al, "A Compact, Short-pulse Laser for Near-field, Range-gated Imaging," in Proc. of SPIE 22nd International Congress on High-Speed Photography and Photonics, Santa $\mathrm{Fe}, \mathrm{NM}, 1996$.

4 F. J. Zutavern et al, "Optically-Activated GaAs Switches for Compact Accelerators", Proc. 22nd Power Modulator Symposium, Boca Raton, FL, June 24-27, 1996, pp. 31-34.

5 For general PCSS references see High-Power Optically Activated Solid- State Switches, A. Rosen and F. J. Zutavern, Eds., Artech House, Boston, 1993.

6 For prior reference on switch longevity see G. M. Loubriel, et al, "Longevity of Optically Activated, High Gain GaAs Photoconductive Semiconductor Switches," to be published in IEEE Transactions on Plasma Science. 